\title{
Abnormal Retinal Optic Nerve Morphology in Young Adults after Intrauterine Growth Restriction
}

\author{
DAVID LEY, KAREL MARŚÁL, JOVANNA DAHLGREN, AND ANN HELLSTRÖM \\ Departments of Pediatrics [D.L.] and Obstetrics and Gynecology [K.M.], Lund University Hospital, 221 \\ 85 Lund, Sweden; and Department of Clinical Neurosciences [J.D., A.H.], Section of Ophthalmology and \\ International Pediatric Growth Research Center, Sahlgrenska University Hospital/East, 41685 \\ Gothenburg, Sweden
}

\begin{abstract}
ABST
Intrauterine growth restriction (IUGR) is a recognized risk
factor for neurologic deficits later in life. Abnormal fetal blood
flow in the presence of fetal growth retardation helps to distin-
guish true fetal growth impairment from small but normally
grown infants. The present study aimed to investigate the influ-
ence of IUGR with abnormal fetal blood flow on retinal optic
nerve morphology at 18 y of age. A prospective study was
performed in 19 subjects with IUGR [abnormal fetal aortic blood
flow velocity; median birth weight deviation of $-31 \%$ ( -22 to
$-42 \%$; median (range)] and in 23 subjects with a normal birth
weight for gestational age [normal fetal aortic blood flow veloc-
ity; median birth weight deviation of $-2 \%$ ( -10 to $22 \%$ )]. All
subjects were previously examined concerning minor neurologic
dysfunction (MND) at 7 y of age. The ocular fundus was
examined by ophthalmoscopy, and the optic nerve morphology
was evaluated by digital image analysis. Decrease in neuroretinal
rim area at 18 y of age was associated with increasing negative
\end{abstract}
Intrauterine growth restriction (IUGR), resulting in birth weight that is small for gestational age (SGA), is a recognized risk factor for neurologic deficits later in life $(1,2)$. The most frequent cause of IUGR is impaired placental function with increased resistance to flow, reflected in abnormal Doppler velocimetry of the umbilical and fetal circulation. The blood flow velocity changes are consistent with experimental findings of redistribution of blood flow in IUGR as well as in fetal hypoxia $(3,4)$. We previously showed that abnormal fetal blood flow in fetuses with IUGR is associated with minor neurologic dysfunction and impaired intellectual function at $7 \mathrm{y}$ of age

Received February 11, 2003; accepted December 1, 2003.

Correspondence: David Ley, M.D., Ph.D., Department of Pediatrics, Lunds University Hospital, 22185 Lund, Sweden; e-mail: david.ley@skane.se

This work was supported by grants from the Swedish Medical Research Council (7905, 10863, 4732, 14940, and 5980), The First of May Flower Foundation, The Segerfalk Foundation, The Medical Faculty of Lund University, and The Gothenburg Medical Society.

DOI: 10.1203/01.PDR.0000129660.32875.09 birth weight deviation $(r=0.71, p<0.0001)$. The subjects with severe MND at $7 \mathrm{y}$ had a reduced neuroretinal rim area [median (range), $\left.1.57 \mathrm{~mm}^{2}\left(1.37-1.78 \mathrm{~mm}^{2}\right)\right]$ compared with those with less severe MND [1.94 $\left.\mathrm{mm}^{2}\left(1.33-2.71 \mathrm{~mm}^{2}\right)\right]$ and with those with normal neurologic function $\left[2.18 \mathrm{~mm}^{2}\left(1.75-2.70 \mathrm{~mm}^{2}\right) ; p\right.$ $<0.05$ and $p<0.0001$, respectively]. A decrease in neuroretinal rim area reflects either a reduction in axonal volume or a decrease in the number of axons in the optic nerve. It is yet unclear whether this finding represents neuronal changes within other cerebral regions in subjects with IUGR. (Pediatr Res 56: 139-143, 2004)

BFC, blood flow class

Abbreviations

IUGR, intrauterine growth restriction

MND, minor neurological dysfunction

SGA, small for gestational age
$(5,6)$. The underlying mechanisms whereby IUGR with abnormal fetal blood flow leads to neurologic impairment are largely unknown. Changes in brain structure have been noted in infants who are born SGA, showing reductions in whole brain weight, cerebellar weight, and hemispheric volume (7-9). Experimental studies on IUGR induced by a reduction of placental blood flow have shown a reduced number of neurons in the hippocampus and cerebellum and signs of decreased myelination (10,11). We have tested the hypothesis that IUGR, characterized as SGA fetus with abnormal aortic blood flow velocity wave form, is associated with abnormal neural morphology by analyzing retinal optic nerve morphology in young adults who were serially examined during fetal life with ultrasonic measurements of growth and blood flow velocity.

\section{METHODS}

The subjects were part of two cohorts examined prospectively during fetal life over a $3-y$ period, 1982-1985, at the 
Department of Obstetrics and Gynecology in Malmö and again at $7 \mathrm{y}$ of age with a neurodevelopmental evaluation $(5,12,13)$. All subjects were examined serially with ultrasound biometry and Doppler velocimetry with measurements of fetal growth and aortic blood flow velocity during the last trimester of pregnancy. The blood flow velocity wave form of the fetal aorta was transformed into a semiquantitative variable, blood flow class (BFC), according to the degree of reduction of the diastolic component of the wave form. Fetal aortic BFC was defined according to the result of the last measurement performed before delivery. Results from fetal blood flow velocity measurements were not clinically available, i.e. they did not influence the timing of delivery and clinical management. At $7 \mathrm{y}$ of age, an age-specific and standardized neurologic examination according to Touwen (14) was performed focusing on minor neurologic dysfunction (MND), in which results were classified as normal, MND-1 (one to two deviant neurologic susbsystems) or MND-2 (more than two deviant neurologic subsystems) as described in detail previously (5).

For the present study, a total of 42 subjects were examined at a median age of 18.2 y [17-19 y; median (range)]. Nineteen of the subjects -9 men and 10 women - had a suspected fetal growth restriction at 32 weeks' gestational age according to estimated fetal weight by ultrasound and were SGA at birth with a median deviation of weight at birth of $-31 \%(-42$ to $-22 \%$ ) from the gestational age-related mean, at a median gestational age of 38.7 completed wk (35-41 wk). Nine subjects had BFC III (absence of positive flow throughout the major part of diastole and/or reverse flow in diastole), and 10 subjects had BFC II (nondetectable end-diastolic velocity). At $7 \mathrm{y}$ of age, four of these subjects had a normal neurologic examination, nine had MND-1, and six had MND-2. The remaining 23 subjects -13 women and 10 men - had a normal estimated fetal weight, normal aortic BFC, and a weight at birth appropriate for gestational age [AGA; median weight deviation $-2 \%(-10$ to $22 \%)$ ] at a median gestational age of 39.7 completed wk (36-42 wk). At 7 y of age, 17 of these subjects had a normal neurologic examination, 4 had MND-1, and 1 had MND-2.

Subjects were examined at the Department of Ophthalmology, Malmö University Hospital, with ocular fundus photography and investigation of visual acuity. The photographs were analyzed quantitatively, using digital image analysis (15). The optic disc area was measured by marking the outlines with a cursor. The inner border surrounding the nerve tissue defined the optic disc; care was taken not to include the white peripapillary scleral ring. The cup was defined by contour, and its definition was facilitated by the course of the vessels and its pallor. The neuroretinal rim area was obtained by subtraction of the cup area from the disc area (Fig. 1). The mean of the measurements from the two eyes in one subject represented the value of each ocular fundus variable. Ocular fundus photography and digital image analysis were performed by two different examiners [digital image analysis was performed by a person who was blinded to the identity of the subjects (A.H.)]. The study was approved by the Committee for Research Ethics at Lund University, and informed consent was obtained from each subject.

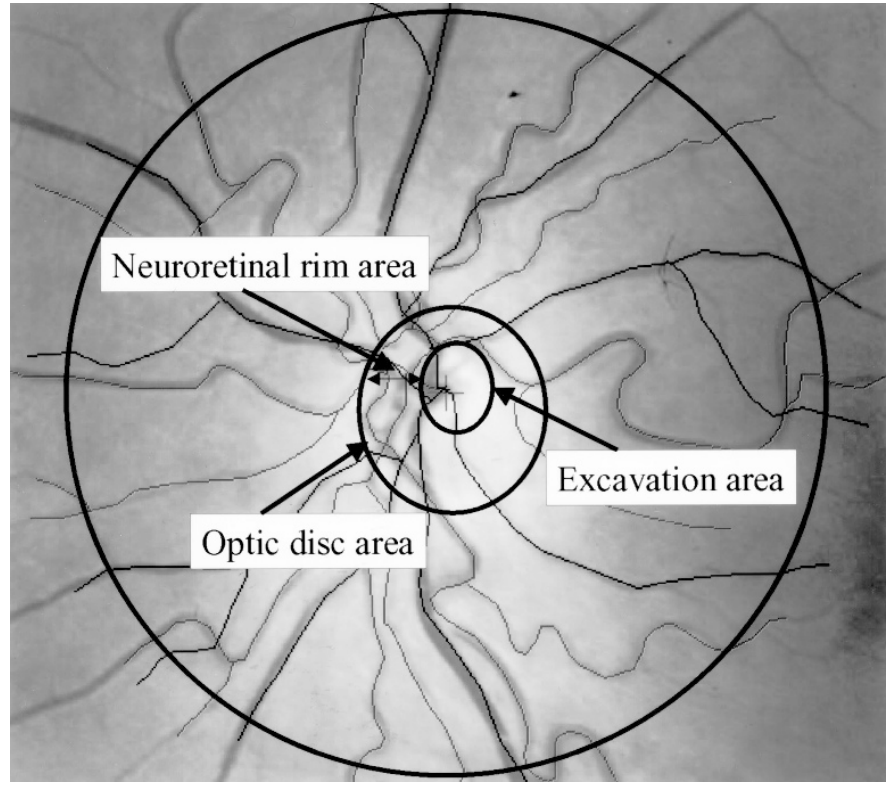

Figure 1. Drawing of the ocular fundus illustrating limits for optic disc area, excavation area, and neuroretinal rim area.

Statistical methods. Intergroup differences were analyzed with the Mann-Whitney $U$ test. Correlation between continuous variables was determined using linear regression analysis. Adjustment for the effect of multiple variables was performed using multiple regression analysis. A $p<0.05$ was considered significant.

\section{RESULTS}

Age, weight, height, and head circumference at follow-up in the SGA and appropriate for gestational age groups, respectively, are given in Table 1. The relationship between neuroretinal rim area and birth weight deviation is shown in Figure 2 and illustrated in Figure 3. Within the entire group $(n=42)$, a decrease in birth weight deviation was associated with a decrease in neuroretinal rim area $(r=0.71, p=0.0001)$. Neither age at examination nor gender was associated with neuroretinal rim area. Neuroretinal rim area remained significantly associated with birth weight deviation when adjusted for gestational age at birth using multiple regression analysis $(r=$ $0.71, p=0.0001)$. The relationship between fetal aortic BFC and neuroretinal rim area is shown in Figure 4. The subjects with fetal aortic BFC III had a reduced neuroretinal rim area [1.59 $\mathrm{mm}^{2}\left(1.33-1.86 \mathrm{~mm}^{2}\right)$; median (range)] compared with those with fetal aortic BFC II [1.85 $\left.\mathrm{mm}^{2}\left(1.37-2.13 \mathrm{~mm}^{2}\right)\right]$ and with those with normal fetal aortic BFC $\left[2.22 \mathrm{~mm}^{2}(1.70-2.71\right.$ $\left.\mathrm{mm}^{2}\right) ; p<0.05$ and $p<0.0001$, respectively].

The relationship between neurologic function at $7 \mathrm{y}$ of age and neuroretinal rim area at $18 \mathrm{y}$ of age is shown in Figure 5. The subjects with MND-2 had a reduced neuroretinal rim area $\left[1.57 \mathrm{~mm}^{2}\left(1.37-1.78 \mathrm{~mm}^{2}\right)\right.$; median (range)] compared with those with MND-1 $\left[1.94 \mathrm{~mm}^{2}\left(1.33-2.71 \mathrm{~mm}^{2}\right)\right]$ and with those with normal neurologic function $\left[2.18 \mathrm{~mm}^{2}(1.75-2.70\right.$ $\left.\mathrm{mm}^{2}\right) ; p<0.05$ and $p<0.0001$, respectively]. There was no significant difference regarding visual acuity between the two groups. Individuals with BFC II-III had a median (range) 
Table 1. Age, weight, height, and head circumference at follow-up according to birth weight for gestational age

\begin{tabular}{lccc}
\hline & AGA $(n=23)$ & SGA $(n=19)$ & $\begin{array}{c}\text { Significance of } \\
\text { difference }(p)\end{array}$ \\
\hline Age [y; median (range)] & $18.1(16.9-19.2)$ & $18.1(16.8-19.3)$ & NS \\
Weight [kg; median (range)] & $70.5(48.0-91.5)$ & $60.0(40.0-97.5)$ & NS \\
Height [cm; median (range)] & $169(158-188)$ & $165(152-182)$ & NS \\
Head circumference [cm; median (range)] & $55.5(52.0-59.0)$ & $54.8(52.0-57.5)$ & NS \\
\hline
\end{tabular}

AGA, appropriate for gestational age.

A
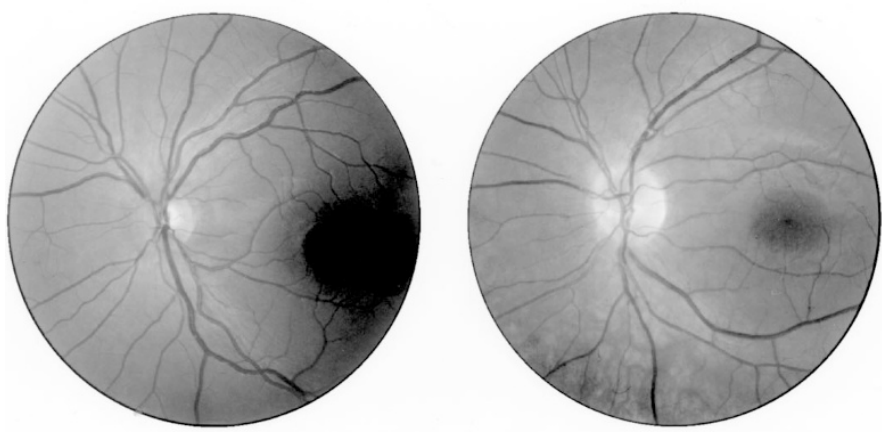

Figure 2. (A) Reduced neuroretinal rim area of the optic nerve in a 18-y-old man with a birth weight SGA and fetal aortic BFC III. (B) Normal-sized neuroretinal rim area of the optic nerve in a 18 -y-old man with normal birth weight and normal fetal aortic BFC.

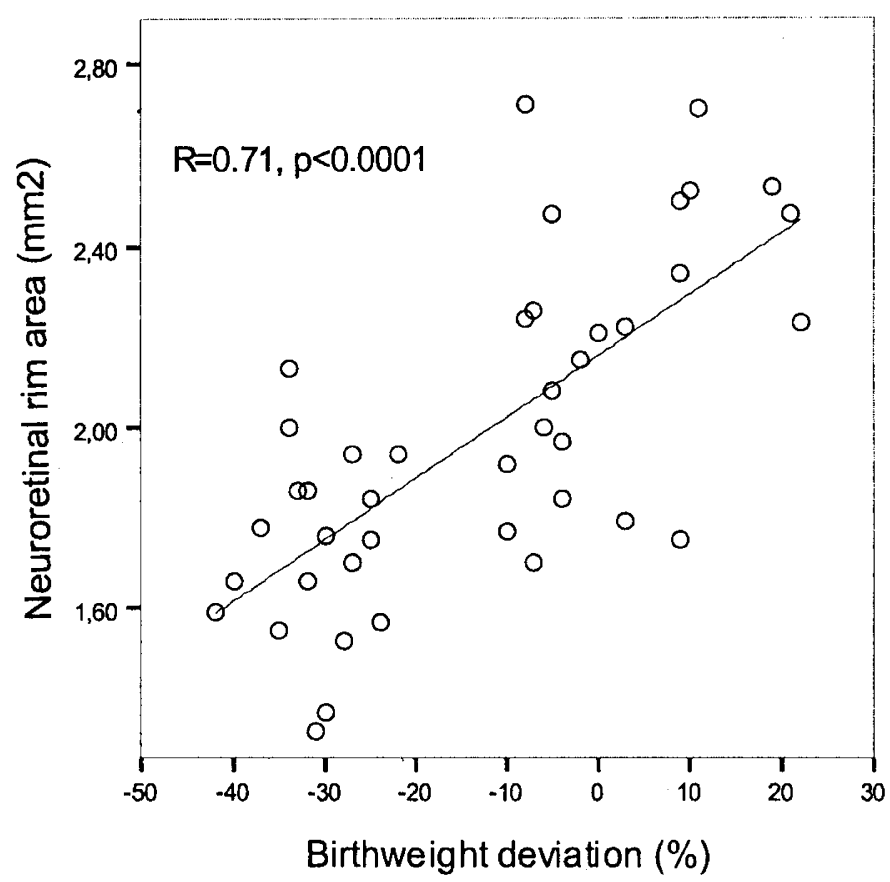

Figure 3. Neuroretinal rim area of the optic nerve in relation to deviation in birth weight ( $\%$ deviation from the mean of the normal population).

visual acuity of $1.29(1-1.6)$, and individuals with BFC 0 had a median (range) visual acuity of $1.20(0.83-1.6)$.

\section{DISCUSSION}

Our findings indicate that SGA birth weight as a result of IUGR is followed by a reduced axonal area in the optic nerve

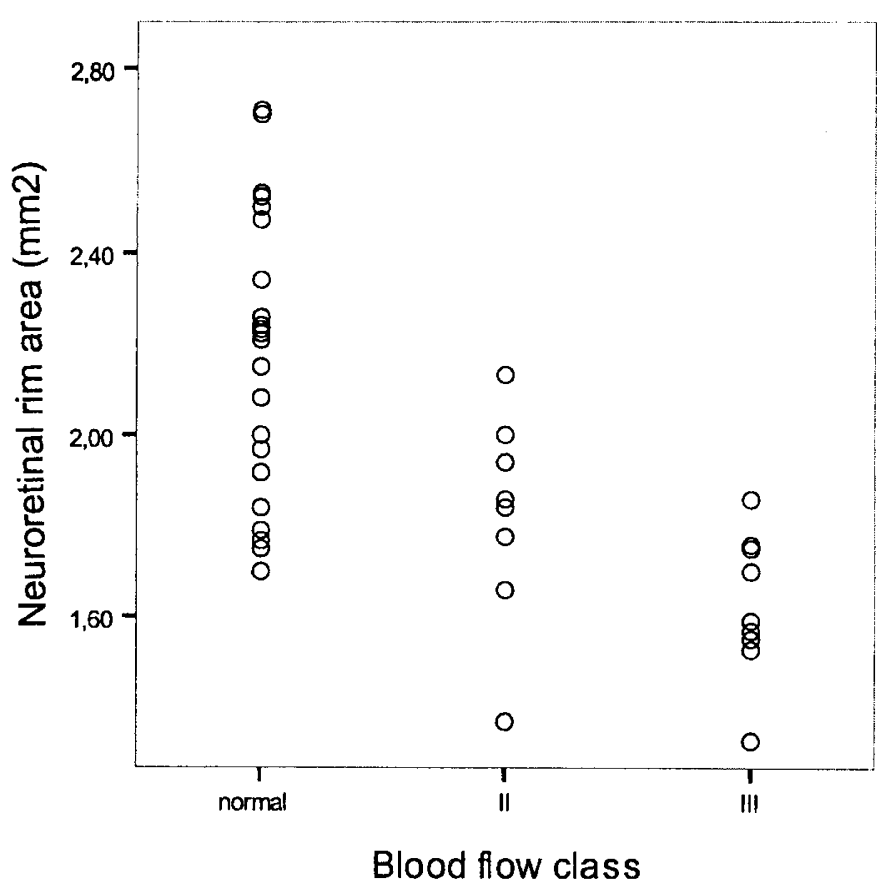

Figure 4. Neuroretinal rim area of the optic nerve in relation to fetal aortic BFC.

at young adult age. Degree of deviation in weight at birth and extent of fetal blood flow velocity abnormality both were associated with an increased reduction of the axonal area of the optic nerve. We could also show that subjects with previously detected severe minor neurologic dysfunction at $7 \mathrm{y}$ of age all had a significantly reduced axonal area.

The present study was performed at an age when continued growth of the optic nerve is unlikely as histologic and clinical studies have shown that there is no measurable growth of the optic nerve after $3 \mathrm{y}$ of age $(15,16)$. The observed reduction in axonal area in subjects with IUGR may reflect either reduced axonal growth with a reduction of axonal volume or a decrease in the number of axons, i.e., in the number of neurons. Experimentally growth restricted fetal guinea pigs had signs of delayed myelination with a reduced density of myelinated axons in the optic nerve when examined shortly before term (17). In addition, these changes were accompanied by a reduced width of cellular layers in the retina and an unaffected number of neurons in the ganglion cell layer (higher density but reduced retinal area), suggesting a reduction in the growth of the neuropile. It cannot be excluded that the reduced axonal area of the optic nerve, found in the present study, is a result of an overall reduced growth of the retinal neuropile. There was 


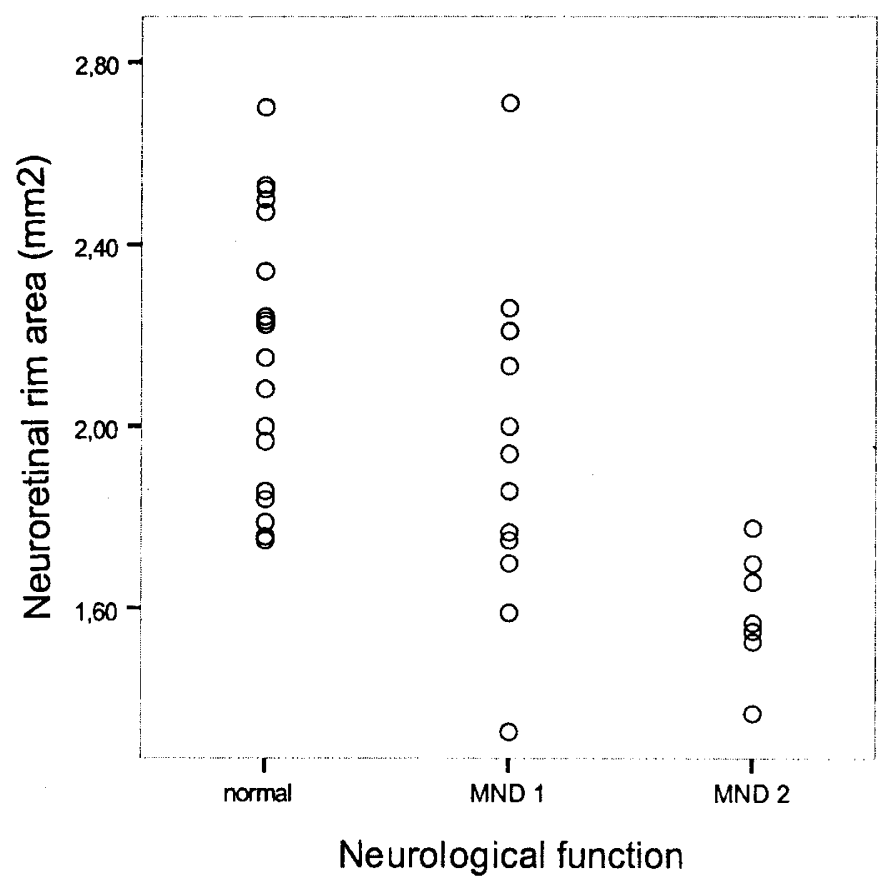

Figure 5. Neuroretinal rim area of the optic nerve in relation to neurologic function at $7 \mathrm{y}$ of age.

no measurable functional deficit regarding visual acuity; data on visual field perception will be studied further.

Several lines of evidence suggest that myelination may be altered in subjects with IUGR. Growth-retarded fetal sheep had a disproportionate reduction in myelin of axons in the optic nerve, whereas the trochlear nerve was not similarly affected, suggesting alteration in oligodendrocyte activity in fetal growth restriction (18). Studies on visual evoked potential latencies in infants born SGA have shown conflicting results, reporting both prolonged and shorter latencies, suggesting alterations in myelination but in opposite directions $(19,20)$. Studies using magnetic resonance imaging have shown signs of decreased or highly variable myelination in infants with IUGR $(21,22)$

It is unclear whether the observed reduction in axonal area is restricted to the optic nerve tract or represents a more global affection of neuronal growth within the brain. The strong association between MND detected at $7 \mathrm{y}$ of age and reduced axonal area suggests that other regions of the CNS might be affected. The subjects with severe MND had among other deviations consistent abnormalities in test items that measure coordination and balance, suggestive of changes in the cerebellum or basal ganglia (5). Experimental studies on induced fetal growth restriction during late pregnancy in guinea pigs and fetal sheep have shown a reduction in volume of cerebellar layers and in the number of Purkinje neurons in the cerebellum $(10,23)$. Neuroradiologic studies on humans after IUGR with volumetric quantification of the cerebellar region have to our knowledge not yet been performed.

Several mechanisms may be considered as causes for the observed reduction in axonal area of the optic nerve. The abnormal aortic fetal blood flow velocity wave form has in several experimental and clinical studies been shown to be associated with fetal hypoxia in terms of fetal distress (24-26). A reduction in mean fetal aortic velocity has been correlated with hypoxia in the IUGR fetus, blood gas values being obtained by cordocentesis (27). Fetal hypoxemia in the subjects of the present study thus might have affected neuronal growth or development during a vulnerable period, resulting in reduced axonal area.

Fetal malnutrition during IUGR may be an important factor in disturbing cellular growth and differentiation in the CNS. Undernutrition in rodents during early life results in reduced brain weight, reduced total cell number, and reduced myelination (28). Trophic factors such as IGF-I are essential for cellular growth and differentiation as well as for tissue repair after a damaging insult. Undernutrition in humans and in experimental animals decreases IGF-I expression in many tissues and in the circulation $(29,30)$. Circulatory levels of IGF-I have been shown to be decreased in SGA fetuses and in fetuses with abnormal blood flow velocity $(31,32)$.

Abnormal fetal blood flow velocity in IUGR, which was present in the subjects with low birth weight for gestational age in the present study, is a proof of placental cause of IUGR with resulting fetal hypoxemia and altered nutrition. A reduction in oxygen delivery to the brain and nutritional deprivation during fetal life are possible mechanisms for our finding of reduced axonal area in the optic nerve at young adult age.

Acknowledgments. We thank Eva Maly, MD (Department of Ophthalmology, Malmö University Hospital); Ann Thuring, Marie-Louse Christensen, and Karina Liuba (Department of Obstetrics and Gynecology, Lund University Hospital); and Aimon Niklasson, MD, PhD, and Kerstin Albertsson-Wikland, MD, PhD (Department of Pediatrics, Sahlgrenska University Hospital), for valuable assistance and discussion.

\section{REFERENCES}

1. Fitzhardinge PM, Steven EM 1972 The small for date infant. II. Neurological and intellectual sequelae. Pediatrics 50:50-57

2. Hadders-Algra M, Huisjes HJ, Touwen BC 1988 Preterm or small-for-gestational age infants. Neurological and behavioural development at the age of 6 years. Eur J Pediatr 147:460-467

3. Peeters LL, Sheldon RE, Jones MD, Makowski EL, Mesehia G 1979 Blood flow to fetal organs as a function of arterial oxygen content. Am J Obstet Gynecol 135:637646

4. Creasy RK, Barrett CT, de Swiet M, Kahanpää KV, Rudolph AM 1972 Experimental intrauterine growth retardation in the sheep. Am J Obstet Gynecol 112:566-573

5. Ley D, Laurin J, Bjerre I, Marsal K 1996 Abnormal fetal aortic velocity waveform and minor neurological dysfunction at 7 years of age. Ultrasound Obstet Gynecol $8: 152-159$

6. Ley D, Tideman E, Laurin J, Bjerre I, Marsal K 1996 Abnormal fetal aortic velocity waveform and intellectual function at 7 years of age. Ultrasound Obstet Gynecol $8: 160-165$

7. Chase HP, Welch NN, Dabiere CS, Vasan NS, Butterfield LJ 1972 Alterations in human brain biochemistry following intrauterine growth retardation. Pediatrics 50:403-411

8. Chase HP, Lindsley WF Jr, O’Brien D 1969 Undernutrition and cerebellar development. Nature 221:554-555

9. Toft PB, Leth H, Ring PB, Petersen B, Lou HC, Henriksen O 1995 Volumetric analysis of the normal infant brain and in intrauterine growth retardation. Early Hum Dev 43:15-29

10. Mallard C, Loeliger M, Copolov D, Rees S 2000 Reduced number of neurons in the hippocampus and the cerebellum in the postnatal guinea-pig following intrauterine growth restriction. Neuroscience 100:327-333

11. Nitsos I, Rees S 1990 The effects of intrauterine growth retardation on the development of neuroglia in fetal guinea pigs. An immunohistochemical and ultrastructural study. Int J Dev Neurosci 8:233-244

12. Laurin J, Lingman G, Marsal K, Persson P-H 1987 Fetal blood flow in pregnancies complicated by intrauterine growth retardation. Obstet Gynecol 69:895-902 
13. Lingman G, Marsal K 1986 Fetal central blood circulation in the third trimester of normal pregnancy: longitudinal study. II. Aortic blood velocity waveform. Early Hum Dev 13:151-159

14. Touwen BCL 1979 Examination of the child with minor neurological dysfunction. Clinics in Developmental Medicine, Nr 71, 2nd edition. SIMP/Heinemann Medical Books, London

15. Hellström A, Svensson E 1998 Optic disc size and retinal vessel characteristics in healthy children. Acta Ophthalmol Scand 76:260-267

16. Rimmer S, Keating C, Chou T, Farb MD, Christenson PD, Foos RY, Bateman JB 1993 Growth of the human optic disc and nerve during gestation, childhood, and early adulthood. Am J Ophthalmol 116:748-753

17. Rees S, Bainbridge A 1992 The structural and neurochemical development of the fetal guinea pig retina and optic nerve in experimental growth retardation. Int $\mathrm{J}$ Dev Neurosci 10:93-108

18. Rees S, Clark M, Snowden M, Harding R 1990 The effects of intrauterine growth retardation on the structural development of cranial nerves (optic, trochlear) in fetal sheep. Int J Dev Neurosci 8:133-141

19. Kjellmer I, Thordstein M, Wennergren M 1992 Cerebral function in the growthretarded fetus and neonate. Biol Neonate 62:265-270

20. Scherjon S, Oosting H, de Visser BW, de Wilde T, Zondervan HA, Kok JH 1996 Fetal brain sparing is associated with accelerated shortening of visual evoked potential latencies during early infancy. Am J Obstet Gynecol 175:1569-1575

21. Suhonen-Polvi H, Maatanen H, Alanen A, Katevuo K, Tenovuo A, Kero P, Kormano M 1998 Examination of infant brain maturation using ultralow field MRI. Acta Paediatr Scand 77:509-515

22. Morgan B, Finan A, Yarnold R, Petersen S, Horsfield M, Rickett A, Wailoo M 2002 Assessment of infant physiology and neuronal development using magnetic resonance imaging. Child Care Health Dev 1:7-10
23. Mallard EC, Rees S, Stringer M, Cock ML, Harding R 1998 Effects of chronic placental insufficiency on brain development in fetal sheep. Pediatr Res 43:262270

24. Malcus P, Hökegård K-H, Kjellmer I, Lingman G, Marsal K, Rosen K-G 1991 The relationship between arterial blood velocity waveforms and acid-base status in the fetal lamb during experimental asphyxia. J Matern Fetal Investig 1:29-34

25. Jouppila P, Kirkinen $P 1984$ Increased vascular resistance in the descending aorta of the human fetus in hypoxia. Br J Obstet Gynecol 91:853-856

26. Lingman G, Laurin J, Marsal K 1986 Circulatory changes in fetuses with imminen asphyxia. Biol Neonate 49:66-73

27. Soothill PW, Nicolaides KH, Bilardo CM, Campbell S 1986 Relation of fetal hypoxia in growth retardation to mean blood velocity in the fetal aorta. Lancet 2:1118-1120

28. Balasz R, Jordan T, Lewis PD, Patel AJ 1986 Undernutrition and brain development. In: Falkner F, Tanner JM (eds) Human Growth. Plenum Press, New York, pp 415-474

29. Thissen J-P, Ketelslegers J-M, Underwood LE 1994 Nutritional regulation of the insulin-like growth factors. Endocr Rev 15:80-101

30. Lowe WL Jr, Adamo M, Werner H, Roberts CT Jr, LeRoith D 1989 Regulation by fasting of rat insulin-like growth factor 1 and its receptor: effects on gene expression and binding. J Clin Invest 84:619-626

31. Larsen T, Main K, Andersson AM, Juul A, Greisen G, Skakkebaek NE 1996 Growth hormone, insulin-like growth factor I and its binding proteins 1 and 3 in last trimester intrauterine growth retardation with increased pulsatility index in the umbilical artery. Clin Endocrinol (Oxf) 45:315-319

32. Spencer JA, Chang TC, Jones J, Robson SC, Preece MA 1995 Third trimester fetal growth and umbilical venous blood concentrations of IGF-1, IGFBP-1 and growth hormone at term. Arch Dis Child Fetal Neonatal Ed 73:F87-F90 